\section{Crítica al screening precoz. Postverdad en medicina}

Gironés Muriel, $\mathrm{A}^{\mathrm{a}}$

a)Hospital Universitario Sanitas La Moraleja

\section{Resumen}

En este trabajo el autor se suma a cuestionar al screening o el diagnóstico precoz del cáncer como paradigma de la medicina bien hecha. Este artículo puede considerarse una crítica frente a la medicina realizada a golpe de protocolos y sin un análisis serio de las distintas herramientas que las matemáticas ofrecen a través de la epidemiología y la estadística.

\section{Introducción}

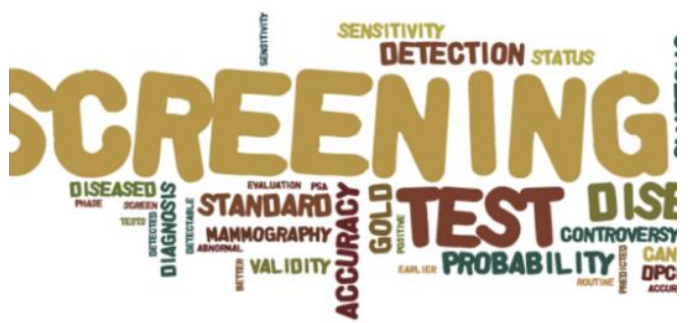

Escribo sabiendo que tiro piedras sobre mi propio tejado. Pero qué le vamos a hacer. La ASA hizo lo mismo cuando propuso una clasificación de ciertas anestesias llamándolas sedaciones y muy pocos pusieron el grito en el cielo. Así que hoy me sumo a cuestionar al screening o el diagnóstico precoz del cáncer como paradigma de la medicina bien hecha.

El ser humano tiene una adhesión inquebrantable a las creencias, aunque estas sean falsas. Las ilusiones acerca de la experiencia humana son comunes y cuando estas se instalan en nuestro inconsciente colectivo en forma de mito es casi imposible erradicarlas. Cuando esas ideas colectivas se circunscriben en el ámbito de la medicina se convierten también en mitos científicos, persistiendo a pesar de que la posterior evidencia científica muestre que son falsos. Son creencias que los propios médicos se niegan a disipar. Nicholas Kirschner nos habla de la "interpretation creep" un término que es utilizado cuando surgen mitos originados en la extrapolación de conclusiones nacidas de la investigación de otros. Se puede originar así una mala extrapolación de resultados y producir una serie de mitos correosos e impermeables a la verdad, pues una vez llegado a un punto, cuantas más evidencias echas sobre ellos su núcleo se vuelve más duro y su persistencia obtinada.

Así, Corea del Sur se convirtió en uno de los países en el que el cáncer de tiroides es el más común. Su tasa se disparó de los 5 casos/100.000 habitantes de 1999 hasta los 70 casos/100.000 habitantes en 2011. Todo este espectacular incremento originado tras un "exitoso" programa de salud pública para la detección temprana de este tipo de cáncer a través de un screening ecográfico.

El hecho es que, tras años de programa, se constató cómo casi dos tercios de los casos detectados sufrieron una tiroidectomía. Esto originó un lógico incremento de la morbimortalidad causada por la propia cirugía. También se constató el exponencial aumento del gasto público para el tratamiento de dicha enfermedad.

¿Y cuál es el pequeño problema? Pues que la tasa de mortalidad del cáncer tiroideo siguió siendo la misma frente a la de 1999 (que era, y es, uno cada 100.000 habitantes/año). Y a pesar de que la epidemiología o los tozudos números demuestran que los coreanos hicieron un pan con dos tortas, gastando recursos e 
incrementando la morbilidad, la creencia de que el screening o el cribado precoz del cáncer de tiroides salva vidas permanece inalterable. De nada sirve decir que evidencia actual solo habla de la utilidad de algún tipo de cribado en el cáncer de pulmón, en el colorectal y en el de cérvix. Pudiendo existir la sospecha que el screening en el resto de cánceres sea un mito médico.

Este mito médico ha florecido a partir de un hecho cierto: que la detección temprana de cualquier cáncer aumenta el tiempo de supervivencia, pero obviamos que en muy pocos se salvan realmente vidas (disminución de la mortalidad). Esta creencia nace a partir de los inicios del siglo $\mathrm{XX}$, cuando los médicos se dieron cuenta de que los mejores resultados contra el cáncer se obtenían cuando se actuaba inmediatamente después de la aparición de los primeros síntomas. Pero extrapolar este hecho a que la detección temprana de un cáncer es siempre un beneficio para disminuir la mortalidad es un error convertido en mito indestructible. $\mathrm{Y}$ todo porque confundir mortalidad con supervivencia es algo muy usual.

\section{Mortalidad y supervivencia}

La tasa de supervivencia marca el porcentaje de pacientes que viven un determinado tiempo después de que se les diagnostique una enfermedad, mientras que la tasa de mortalidad marca la proporción de personas que mueren por una enfermedad respecto al total de la población durante un período de tiempo (generalmente se expresa en tanto por mil por año, \%o). Un buen médico les diría que es importante aumentar la tasa de supervivencia de una enfermedad pero si esta no se asocia a un descenso de la tasa de mortalidad lo único que estaríamos haciendo es tratar más tiempo al paciente $\sin$ mejoras reales de resultados. Esto es algo que muchos médicos están actualmente demandando de los servicios sanitarios en una nueva conciencia ética y social que trata de salvar la sostenibilidad de los sistemas sanitarios (ahora en peligro). $\mathrm{Y}$ es que, el gasto sanitario de las naciones ha aumentado de manera imparable e implacable por encima del crecimiento de las mismas naciones sin una mejora notable de la salud de sus poblaciones desde hace décadas. Se puede ver como la tasa de mortalidad del cáncer en el mundo occidental no ha variado mucho. Tan solo se observa un gasto creciente pero nada efectivo, y por lo tanto, un crecimiento inútil que hace desperdiciar entre un 21 y el $47 \%$ del presupuesto que podía ser transferido a una verdadera investigación del problema como refiere Donald Berwick, entre otros.

\section{Rompiendo mitos}

Anthony Miller, dirigió durante 25 años un estudio; el Canadian National Screening Study (1), con casi 90.000 mujeres entre 40 y 59 años de edad, con él llegó a una serie de conclusiones que chocan frontalmente con el sentir popular que casi todos tenemos sobre el screening del cáncer de mama.

1- Que las mamografías anuales no reducen la mortalidad por cáncer de mama.

2- 2- Que a nivel poblacional, los beneficios en forma de vidas salvadas no son mayores que los riesgos por tratamientos innecesarios.

La propia Cochrane también nos ofrece un metanálisis (2) tras 5 ensayos aleatorizados, encontrando una evidencia contraria al sentir general sobre el cribado del cáncer de próstata. Tal cribado no parecía disminuir el número de muertes por dicho cáncer; así de claro.

En España también tenemos nuestros sambenitos. Tenemos el cribado del cáncer de colon mediante colonoscopias sin el debido test de sangre oculta en heces como una actitud médica asentada, fomentada y apoyada por muchos estamentos. Se prefiere así la colonoscopia en perjuicio de la determinación de sangre oculta en heces como primer screening, a sabiendas, que esta determinación de sangre oculta ya aporta evidencias científicas de eficiencia y efectividad como cribado precoz del cancer colorectal.

No se ve por ningún lado un adecuado debate sobre cuál sería el mejor protocolo 
para una población de varios millones de españoles. Tenemos hoy una población que ha originado, en los programas de screening mediante colonoscopia que algunas comunidades autónomas han puesto en marcha, una tasa de detección entre 1,5 y 4,4 casos $/ 1000$ personas cribadas (3). Lógicamente la tasa de supervivencia ha aumentado en esa población (al diagnosticarse más casos de enfermedad en un estadío inicial). Pero hay un silencio en aclarar cuál es la verdadera disminución de la tasa de mortalidad y determinar la morbilidad asociada a estos programas. Tampoco existe un debate sobre el sobrediagnóstico ni tampoco sobre cómo encontrar una prueba diagnóstica más sensible y específica frente a los casos más agresivos respecto a los que no lo son. La sociedad impide el debate.

Porque mientras discutimos poco sobre esta cuestión siguen implantándose programas de detección precoz. Todo es apoyado por políticos y gestores, todo es sostenido por una divulgación en medios de comunicación que no plantea la mínima duda entre el coste/beneficio, su efectividad y si realmente mejora la mortalidad. La sociedad actual trata la implantación de pruebas diagnósticas como un derecho ganado a los ciudadanos por encima de su utilidad real. Todo esta fuera de un serio debate científico... y eso es culpa de todos.

\section{El problema}

Y cuando políticos y la opinión pública se resisten a este debate científico surge el problema del gasto. En el caso del cribado del cáncer de colon o en el de mama, el realizar una colonoscopia o una mamografía a toda la población anualmente sin discriminar quién, cómo y por qué, supone realizar miles de pruebas en nuestro país diariamente. Esto incrementa listas de espera, recursos y puestos de trabajo dedicados a ello. El problema llega cuando hay que pagar ese gasto en tiempos de crisis.

Como vemos actualmente, la solución tomada frente a situaciones de crisis es el recorte del gasto por prueba, aunque sea a costa de recortar en seguridad y calidad del procedimiento. Y cuando el disminuir el gasto por prueba no es suficiente, la remuneración del médico se torna entonces excesiva para muchos. Se le ofrece así remunerarle por lo que hace y no por lo que sabe, entrando en una espiral especulativa en la que siempre existirá alguien dispuesto a hacer lo mismo por menos sin importar las más elementales reglas de calidad y seguridad.

Este artículo no puede considerarse una crítica al cribado del cáncer. No nos equivoquemos. La propia evidencia apoya ciertos screening o cribados en ciertos tipos de cáncer, como son el de pulmón, el de cérvix y el de colon. No soy un antivacunas o un holístico trasnochado. Es una crítica al cómo se hace y a las consecuencias sobre la sostenibilidad del sistema si este no se hace sin un espíritu crítico. Algo que nos afecta a todos.

Este artículo sí puede considerarse una crítica frente a la medicina realizada a puro golpe de protocolos y sin un análisis serio. Una crítica hacia la medicina que olvida: que las herramientas no son el fin pero que es preciso conocerlas para constituir una base sólida sobre la que ejercer nuestra profesión como médicos. En este caso el confundir la tasa de supervivencia con la de mortalidad cuando se analizan los resultados de un cribado nos lleva a gestionar mal los recursos y no implementar salud en la población, algo éticamente reprobable.

Jonh Loannidis, epidemiólogo de Stanford, en California, nos advierte que muy pocas pruebas de detección de 19 enfermedades graves reducen realmente la mortalidad de la misma (4). Podemos pasar años discutiendo sobre la edad adecuada de un cribado sin pararnos a pensar siquiera si dicha prueba es la adecuada. Lo peor de todo es que la falta de duda constructiva y el seguidismo médico consiguen una merma de los ya escasos recursos y del tiempo disponible para dedicarnos a lo realmente importante. ¿Por qué discutimos sobre la edad de inicio de una mamografía en vez de buscar una prueba que detecte realmente los tumores que se comportarán de manera más agresiva? Me quedo con la 
afirmación de Gilbert Welch, del Instituto Darthmouth de Políticas de Salud y Práctica Clinica en Lebanon, cuando afirma que: "el screening se ha convertido en una forma fácil para el médico y para el paciente de autoconvencerse de que están haciendo algo por la salud cuando el riesgo de contraer un cáncer no ha disminuido en absoluto".

La verdadera política sanitaria se consigue implantando modos de vida saludables, atender a la crítica y a la evidencia, investigando. No implementando programas ambiciosos que no mejoran la supervivencia y que sólo pueden ser sufragados mediante el recorte de personal sanitario y mermando su justa remuneración.

\section{Bibliografía para saber más}

1. Miller AB, Wall C, Baines CJ, Sun P, To T, Narod SA. Br Medicine J. 348, G366 (2014) (PubMed) (HTML) (HTML2) (ePub) (PDF)

2. Llic, D, Neuberger, NM et al. Cochrane Database Sys Rev 1 CD004720 (2013) (PubMed)

3. Xavier Castell, Sala M, Salas D, Ascunce N, Zubizarreta R, Casamitjana M. Gaceta Sanitaria 23(3),244-249, (2009) (PubMed) (HTML)

4. Saquib N, Saquib J Loannidis JPA Epidemiol 44, 264-277 (2015) (PubMed) (HTML) (PDF)

Correspondencia al autor

Alberto Gironés Muriel agirones@gmail.com

Hospital Universitario Sanitas La Moraleja, Madrid.

Aceptado para blog en junio de 2017. 